\title{
TRANSIÇÃO METABÓLICA NO TESTE PROGRESSIVO DE PESSOAS TREINADAS COM MUSCULAÇÃO E CORRIDA
}

\author{
METABOLIC TRANSITION IN TRAINED PEOPLE IN PROGRESSIVE TEST WITH RESISTANCE \\ TRAINING AND RUNNING \\ TRANSICIÓN METABÓLICA EN PERSONAS ENTRENADAS PARA PRUEBA PROGRESIVA CON \\ MUSCULACIÓN Y CARRERA
}

Artigo Original

ORIGINAL ARTICLE

Artículo Original

\author{
Jhennyfer Aline Lima Rodrigues' \\ (Educador Físico) \\ Anselmo José Perez' \\ (Educador Físico) \\ Wellington Lunz' (Educador Físico) \\ José Geraldo Mill' (Médico) \\ Luciana Carletti' (Educador Físico)
}

1. Universidade Federal do Espírito Santo, Vitória, ES, Brasil.

\section{Correspondência:}

Laboratório de Fisiologia do Exercício (LAFEX) - UFES. Av. Fernando Ferrari, 514, Goiabeiras. Vitória, ES, Brasil. 29075-91. jhenny.jf@gmail.com

\section{RESUMO}

Introdução: A especificidade das adaptações cardiorrespiratórias e metabólicas do treinamento aeróbio e de força evocam respostas distintas durante o teste cardiopulmonar de exercício (TCPE). Objetivo: Descrever o comportamento cardiorrespiratório durante a transição metabólica (TM) do TCPE, de praticantes de corrida e musculação, comparados a um grupo controle. Métodos: Homens de 21 a 55 anos foram agrupados em: grupo de corredores $(G C, n=30)$, grupo de musculação $(G M, n=23)$ e grupo controle (GCON, $n=38)$. Foram submetidos à avaliação antropométrica e TCPE com análise do limiar anaeróbio ventilatório (LAV) e do ponto de compensação respiratória (PCR). Calculou-se a economia de corrida pela relação entre $\mathrm{VO}_{2}$ e velocidade do teste ( $\mathrm{EC}_{\mathbb{I N C L N N A}}$ ). Resultados: Na fase de transição metabólica, a carga $(\mathrm{km} / \mathrm{h})$ foi superior no GC $(4,2 \pm 1,6)$ vs. GCON $(2,7$ $\pm 1,6)$ e $G M(2,8 \pm 1,0) ; P<0,05$. O GC apresentou maior $V_{2 L A v i} V_{2} O_{2 P C R}$ e VO $O_{2 M A X} .(36 \pm 8 ; 46 \pm 8 ; 51 \pm 8$ vs. $24 \pm$ $6 ; 35 \pm 5 ; 40 \pm 6$ e $26 \pm 6 ; 35 \pm 6 ; 40 \pm 7$ ml.kg $\left.{ }^{-1} . \mathrm{min}^{-1} ; P<0,05\right)$, comparado com GCON e GM, respectivamente, mesmo após a correção alométrica. A F $C_{\text {REp }}$ foi menor entre GC e GCON (CE $=52 \pm 6$; CON $=60 \pm 8$ bpm; $P<0,05)$. Na fase de TM, O GC apresentou maior aumento da carga de trabalho e menor alteração do pulso de oxigênio comparado ao GCON e ao GM. O VO 2 durante a TM não difere entre os grupos. O GC apresentou menor $E C_{\text {INCLNNA }}$ nos instantes finais do teste, comparado a GCON e GM. Conclusão: O GC apresentou maior eficiência metabólica nas transições progressivas de intensidade de esforço em relação a GCON e GM e o GM não exibe capacidade de transição aprimorada no TCPE, até mesmo quando comparados a indivíduos sedentários.

Palavras-chave: treinamento de resistência, corrida, metabolismo energético, limiar anaeróbio.

\section{ABSTRACT}

Introduction: The specificity of cardiorespiratory and metabolic adaptations of aerobic and strength training evoke different responses during cardiopulmonary exercise testing (CPET). Objective: To describe the cardiorespiratory behavior during metabolic transition (MT) of CPET, runners and bodybuilders compared to a control group. Methods: Men aged 21-55 years were grouped as follows: runners group ( $R G, n=30)$, strength group ( $S G, n=23$ ) and control group ( $C G, n=38)$. The subjects underwent anthropometric and CPET assessment with analysis of ventilatory anaerobic threshold (VAT) and the respiratory compensation point $(R C P)$. We calculated the running economy by the relationship between $\mathrm{VO}_{2}$ and test speed (EC INCLINA). Results: In metabolic transition phase, the running speed ( $\mathrm{km} / \mathrm{h}$ ) was higher in the $R G$ group (4.2 \pm 1.6$)$ vs.

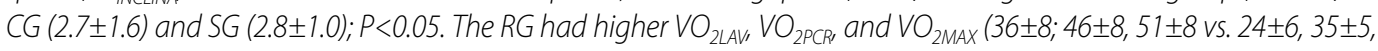
$40 \pm 6$, and $26 \pm 6,35 \pm 6,40 \pm 7 \mathrm{ml} \cdot \mathrm{kg}^{-1}$. $\left.\mathrm{min}^{-1} ; P<0.05\right)$ compared to group CG and SG, respectively, even after allometric correction. The resting heart rate was lower among $R G$ and $C G(R=52 \pm 6 ; C=60 \pm 8$ bpm, $P<0.05)$. In the MT phase the $R G$ had a greater increase in workload and less change in oxygen pulse compared to $C G$ and $S G$. The $\mathrm{VO}_{2}$ during MT did not differ between groups. The RG showed lower $E C_{\text {INCLNA }}$ in the closing stages of the test compared to CG and SG. Conclusion: The RG showed higher metabolic efficiency in progressive transitions of effort intensity in relation to CG and SG and the SG does not display enhanced transition capacity in CPET, even when compared to sedentary individuals.

Keywords: resistance training, running, energy metabolism, anaerobic threshold.

\section{RESUMEN}

Introducción: La especificidad de las adaptaciones cardiorrespiratorias y metabólicas del entrenamiento aeróbico y de fuerza evoca diferentes respuestas durante la prueba de esfuerzo cardiopulmonar (PECP). Objetivo: Describir el comportamiento cardiorrespiratorio durante la transición metabólica (TM) de la PECP, de corredores y culturistas, en comparación con un grupo control. Métodos: Hombres entre 21 y 55 años fueron agrupados de la siguiente manera: grupo corredores (GC; $n=30)$, grupo culturistas (GCU; $n=23$ ) y grupo control (GCON; $n=38$ ). Los participantes se sometieron a evaluación antropométrica y PECP, con el análisis de umbral anaeróbico ventilatorio (UAV) y el punto de compensación respiratoria $(P C R)$. Se calculó la economía de carrera mediante la relación entre $\mathrm{VO}_{2}$ y velocidad de la prueba $\left(\mathrm{EC}_{\mathbb{I N C L N A}}\right)$. Resultados: En la transición metabólica, la carga ( $\mathrm{km} / \mathrm{h})$ fue mayor en el GC $(4,2 \pm 1,6)$ vs. GCON $(2,7 \pm 1,6)$ y GCU $(2,8 \pm 1,0) ; P<0,05$. El GC

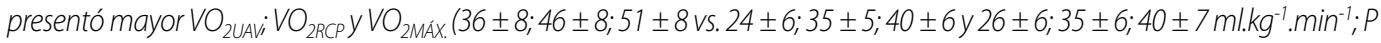

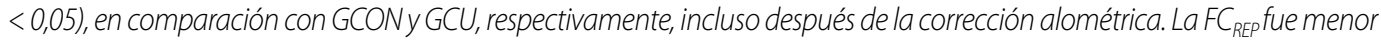
entre GD y GCON (GC = 52 $\pm 6 ; G C O N=60 \pm 8$ bpm; $P<0,05)$. La fase de TM en el GC presentó mayor aumento de carga de trabajo y menos cambios en el pulso de oxígeno en comparación con GCONy GCU. EI VO ${ }_{2}$ durante la TM no difirió entre los 
grupos. El GC mostró menor EC $C_{\text {NCLINA }}$ en los momentos finales de la prueba en comparación con GCON y GCU. Conclusión: EI GC mostró una mayor eficiencia metabólica en las transiciones progresivas de esfuerzo en comparación con GCONy GCU, y GCU no muestra una mayor capacidad de transición en el PECP, incluso en comparación con los individuos sedentarios.

Palabras clave: entrenamiento de resistencia, carrera, metabolismo energético, umbral anaerobio.

\section{INTRODUÇÃO}

A execução de exercícios com finalidade de aprimorar os componentes da aptidão física relacionada à saúde envolve modalidades de condicionamento cardiorrespiratório (aeróbios) e neuromuscular'. Isso porque, classicamente se aceita que as adaptações evocadas pelos programas de condicionamento físico sobre os sistemas fisiológicos estão atreladas à especificidade da modalidade praticada ${ }^{1,2}$. Contudo, nem todos os praticantes de atividade física possuem disponibilidade de tempo ou motivação pessoal para se envolver continuamente em diferentes modalidades de treino.

A especificidade das adaptações cardiorrespiratórias e metabólicas do treinamento aeróbio são bem representadas pelas alterações do limiar anaeróbio ventilatório ( $\mathrm{LAV}$ ) e do $\mathrm{VO}_{2 \mathrm{MÁ}}{ }^{3}$, mensuradas durante um teste cardiopulmonar de exercícios (TCPE). O LAV consiste em um fenômeno especialmente marcante na resposta metabólica ao exercício com aumento progressivo na intensidade, que é a ocorrência de modificação, relativamente abrupta, da relação entre o incremento da ventilação e o do consumo de oxigênio $\left(\mathrm{VO}_{2}\right)^{4}$, sendo um índice que reflete satisfatoriamente a aptidão física ${ }^{5,6}$. Após o LAV, um segundo comportamento diferenciado da ventilação, é notado pela quebra da linearidade, identificada como ponto de compensação respiratória (PCR), também denominado de limiar da acidose láctica ${ }^{3}$ O PCR é caracterizado pelo menor valor do equivalente ventilatório de dióxido de carbono $(\mathrm{VENCO})$, antes do início do seu aumento exponencial ${ }^{7}$, que reflete o ajuste da ventilação que acompanha o aumento do $\mathrm{H}^{+}$arterial ${ }^{8}$. Desta forma, se aceita que o intervalo entre o LAV e o PCR, compreende uma fase isocápnica, onde o ajuste ventilatório atende a demanda elevada de $\mathrm{CO}_{2}$ advindo adicionalmente do mecanismo de tamponamento do bicarbonato ${ }^{8,9}$. Após essa fase espera-se uma redução da pressão do $\mathrm{CO}_{2}\left(\mathrm{PetCO}_{2}\right)$ no ar expirado, demarcando o limite da função do tampão lactato-bicarbonato ${ }^{10}$.

A análise da troca gasosa em nível da ventilação pulmonar, expressa pelos valores de dióxido de carbono produzido $\left(\mathrm{VCO}_{2}\right)$ e de oxigênio consumido $\left(\mathrm{VO}_{2}\right)$, suas relações com a ventilação $\left(\mathrm{VE} / \mathrm{NO}_{2}\right.$ e $\left.\mathrm{VE} / \mathrm{NCO}_{2}\right)$ e pressão desses gases ao final da expiração $\left(\mathrm{PetO}_{2}\right.$ e PetCO $\left.\mathrm{CO}_{2}\right)$, é bem aceita como critério para identificar as etapas de transição do metabolismo, uma vez que já foi validada em comparação com o limiar de lactato, apresentando correlação de 0,953 e 0,979

Sabe-se que, indivíduos treinados que acionam predominantemente o metabolismo aeróbio utilizam maior fração do consumo de oxigênio máximo $\left(V_{2} \mathrm{M}_{2} \mathrm{x}\right.$. $)$, podendo elevar o LAV até cerca de $90 \%$ do $\mathrm{VO}_{2 M A X}{ }^{11}$. Entretanto, o desempenho em eventos aeróbios também requer capacidade de se exercitar por tempo prolongado a uma alta percentagem do $\mathrm{VO}_{2 \mathrm{MÁx}}$, que é reflexo da eficiência de economia de corrida $(E C)^{12-15}$, e elevada capacidade de tamponamento ${ }^{16-18}$. De fato, a melhoria da EC possibilita aos corredores a manutenção de maiores intensidades de esforço por longos períodos de tempo, o que pode estar relacionado ao menor estresse metabólico, o que reflete diretamente sobre os ajustes na estratégia de corrida ${ }^{19,20}$. Nesse sentido, trabalhos prévios ${ }^{20,21}$, determinaram a EC mediante o coeficiente angular gerado a partir da relação $\mathrm{VO}_{2}$ vs intensidade do teste cardiopulmonar de exercício (EC $C_{\text {INCINA }}$ ), o que o torna um parâmetro alternativo empregado para o diagnóstico da aptidão de corredores de provas de longa duração devido sua relação com o metabolismo aeróbio20.

Por outro lado, o treinamento de força, mesmo descrito como um esforço anaeróbio, também evoca estímulos aeróbios nas fases de recuperação do esforço ${ }^{22}$, e ainda, apresenta evidências de aprimoramento da eficiência de corrida para uma mesma velocidade, quando introduzido no programa de treinamento de corredores de endurance ${ }^{22-24}$. Essas evidências nos levam a refletir que, adaptações evocadas pelo treinamento de força, poderiam incidir em melhorias na eficiência do período de transição metabólica.

Portanto, considerando a importância do tema para esclarecer essa lacuna no entendimento dos regimes de treinamento e sua especificidade de adaptações, este estudo objetiva comparar os comportamentos cardiorrespiratórios, durante as fases de transição metabólica do teste cardiopulmonar de exercícios, de praticantes experientes em modalidades que envolvam predominante o metabolismo aeróbio (corredores de endurance); ou anaeróbio, treinados em musculação, tendo como referência um grupo controle.

\section{MÉTODOS}

Participaram do estudo 91 homens aparentemente saudáveis, entre 21 e 55 anos, que preenchiam concomitantemente os seguintes critérios gerais e específicos de inclusão, respectivamente: os sujeitos não eram fumantes e não apresentavam qualquer impedimento de ordem cardiológica, muscular ou articular. Os sujeitos foram alocados em três grupos experimentais: corredores de endurance ( $G C, n=30)$, corredores de rua com no mínimo dois anos de experiência em corrida predominantemente aeróbia de longa distância, com frequência semanal de pelo menos quatro sessões de treinamento, e mínimo de $40 \mathrm{~km}$ percorridos por semana em treinamento; grupo musculação $(G M, n=23)$, praticantes de exercício musculação há no mínimo dois anos sem interrupção, submetidos a um regime de treinamento intenso, comprovado pelo relato dos praticantes, e pelo predomínio de somatotipo de mesomorfia; grupo controle (GCON, n =38), constituído por indivíduos que satisfizeram os mesmos critérios gerais, mas encontravam-se há no mínimo seis meses sem praticar exercícios de forma sistematizada e regular. Todos os participantes desta investigação foram informados textualmente dos possíveis riscos e benefícios intrínsecos aos testes realizados e assinaram o Termo de Consentimento Livre e Esclarecido. A pesquisa foi aprovada pelo Comitê de Ética de Pesquisa em Humanos do Centro de Ciências da Saúde da Universidade Federal do Espírito Santo, (no protocolo 009/10).

\section{Avaliação antropométrica}

Os indivíduos foram avaliados com auxílio de um estadiômetro com precisão de $1 \mathrm{~mm}$ (Seca, modelo 216, Alemanha), e em seguida pesados em uma balança com precisão de 0,01 kg (Toledo, modelo 2096PP, Brasil); por meio dos quais foi calculado o índice de massa corporal. A espessura das dobras cutâneas foi aferida utilizando-se um compasso científico Mitutoyo com precisão de $1 \mathrm{~mm}$ (CESCORF, Brasil). Os valores de cada componente do somatotipo foram derivados das medidas antropométricas: peso, estatura, diâmetros biepicondilar do úmero e joelho direitos, circunferências do braço e perna direitos, e dobras cutâneas tricipital, suprailíaca, subescapular e perna medial, todas do lado direito. As medidas foram utilizadas para compor os graus de endomorfia, mesomorfia e ectomorfia. O somatotipo foi calculado pelo método proposto por Heath e Carter apud Silva e Trindade ${ }^{24}$

Teste Cardiopulmonar de Exercício (TCPE): Em uma sala silenciosa mantida a temperatura ambiente entre 21 e $24^{\circ} \mathrm{C}$, a pressão arterial (PA) era aferida e os indivíduos encaminhados para a esteira onde 
eram equipados com a máscara conectada ao pneumotacômetro para medida do fluxo de ar e análise dos gases expirados. Os indivíduos eram orientados sobre os procedimentos de realização do teste, que incluíam: permanecer respirando normalmente, não usar como apoio o corrimão da esteira durante a caminhada ou corrida, a não ser em caso de necessidade e ao final do teste; solicitar interrupção do teste em caso de dor localizada, ou qualquer outro desconforto.

O teste foi realizado em esteira rolante motorizada (Inbra Sport Super ATL, Porto Alegre, Brasil) mantida com inclinação de 1\% seguindo um protocolo de rampa individualizado, objetivando uma duração entre 10 e 12 minutos. A velocidade era incrementada gradativamente até que o indivíduo atingisse a exaustão. $\mathrm{O}$ incremento da intensidade diferiu entre os grupos. Para o GC iniciava-se o teste a uma velocidade de $6 \mathrm{~km} / \mathrm{h}$ com um incremento de velocidade a cada 15 segundos. Para o GM e GCON o teste iniciava-se a uma velocidade de $5 \mathrm{~km} / \mathrm{h}$ com o incremento de velocidade a cada 15 segundos, calculado pelo software.

As variáveis ventilatórias foram mensuradas utilizando o analisador metabólico de gases (modelo Cortex Metamax 3B, Alemanha), com coleta respiração a respiração, e em seguida calculadas as médias de 20 em 20 segundos, sendo analisados com a ajuda do programa Metasoft. A unidade do Cortex foi calibrada pelo método de circuito fechado, através de gás de calibração (cilindro de $16 \% \mathrm{O}_{2}$ e $5 \% \mathrm{CO}_{2}$ original, fornecido pelo fabricante), o que permitiu uma nova calibragem antes de cada teste.

Os critérios para aceitar o teste como máximo, se resumiram em aceitar pelo menos três dos seguintes critérios: a) exaustão voluntária; b) FC máxima atingida de pelo menos $90 \%$ da prevista para a idade (220-idade); c) razão de troca respiratória igual ou acima de 1,1; d) consumo máximo de oxigênio, observado pelo conceito de platô, quando o VO ${ }_{2}$ estabiliza não ocorrendo uma diferença $\leq 150 \mathrm{ml}^{\mathrm{kg}} \mathrm{kg}^{-1} \cdot \mathrm{min}^{-1}$ entre os valores dos últimos 30 segundos de teste ou pico, quando o $\mathrm{VO}_{2}$ atinge maior valor durante o teste, não ocorrendo estabilização ${ }^{25}$.

Determinação do LAV e PCR: O LAV foi determinado sempre pelos mesmos três avaliadores e de forma independente, utilizando como critério o método visual da perda da linearidade da relação entre o consumo de oxigênio e a produção de dióxido de carbono (V-Slope) ${ }^{3}$. Para apoiar a confirmação do limiar pelo V-Slope, também foi utilizado o ponto mais baixo do equivalente ventilatório de oxigênio $\left(\mathrm{VEN} \mathrm{VO}_{2}\right)$ antes de ele começar a subir, sem aumento concomitante do equivalente ventilatório de dióxido de carbono $\left(\mathrm{VE} / \mathrm{VCO}_{2}\right)$ e o comportamento da PetCO $\mathrm{O}_{2}$ O PCR foi identificado a partir da inspeção gráfica dos dados da $\mathrm{VENO}$ e $\mathrm{VE} / \mathrm{NCO}_{2}$, onde se observava um aumento sistematizado dos equivalentes ventilatórios com confirmação pelo maior valor da PetCO ${ }_{2}$, precedendo sua queda abrupta.

Determinação da fase de transição metabólica (TM): A fase de transição metabólica foi definida como a magnitude de diferença $(\Delta)$ entre o PCR e o LAV para cada variável de interesse. A TM pode ser interpretada como um ajuste metabólico que o organismo realiza à medida que a intensidade do exercício aumenta.

Para minimizar a interferência da massa corpórea no consumo de oxigênio no LAV, PCR e MÁX, utilizou-se a escala alométrica, que obedece a seguinte fórmula:

$$
\mathrm{VO}_{2}=\mathrm{aM}^{\mathrm{b}} \text {, onde: }
$$

a é o coeficiente de proporcionalidade, M é a massa corpórea em kg e b é o expoente, que são valores numéricos obtidos pela expressão logarítmica linear $\left(\log \mathrm{VO}_{2}=\log a+b \times \log M\right)$. Na presente investigação adotou-se o valor de $b=0,73$, conforme trabalho prévio realizado com atletas de 25 diferentes esportes ${ }^{26}$.

$\mathrm{O}$ coeficiente angular gerado a partir da relação $\mathrm{VO}_{2}$ vs intensidade $\left(\mathrm{EC}_{\text {INCLINA }}\right)$, foi determinado dividindo-se o $\mathrm{VO}_{2}\left(\mathrm{ml} \mathrm{kg}^{-1}\right.$. $\left.\mathrm{min}^{-1}\right)$ pela velocidade (km/h) nas intensidades de 20\%, 30\%, 40\%, 50\%, 60\%, 70\%, 80\%, 90\% e $100 \%$ do TCPE.

\section{Análise Estatística}

A normalidade dos dados foi testada com o teste Shapiro Wilk. A análise de variância de uma via (ANOVA one way) foi utilizada para comparação entre os grupos que apresentaram distribuição normal, e quando uma diferença significante foi detectada procedeu-se o teste de comparação múltipla de Tukey Kraemer.

As variáveis que não apresentaram distribuição normal foram tratadas com o teste de Kruskal-Wallis, e quando foi detectada diferença significante entre os grupos foi utilizado o teste de comparação múltipla de Dunn.

A significância estatística foi aceita quando a probabilidade de erro era menor que o valor alfa fixado em 5\%. A análise dos dados foi realizada com o auxílio do software Sigma Stat versão 3.5.

\section{RESULTADOS}

Na tabela 1 são apresentadas as características dos grupos investigados. O peso corporal, o índice de massa corpórea (IMC) foram maiores no grupo GM, quando comparados aos demais grupos. Porém, esse resultado foi acompanhado de maior grau de mesomorfia para o GM, que indica o grau de proeminência muscular desses indivíduos. O grupo GC apresentou média de idade maior quando comparado aos grupos GCON e GM, mesmo com a delimitação da faixa etária para inclusão no estudo, os corredores se concentravam entre os indivíduos de faixa etária superior.

A tabela 2 mostra o comportamento cardiorrespiratório durante o TCPE. O grupo GC apresentou valores superiores de $\mathrm{VO}_{2 L A V} V \mathrm{VO}_{2 \mathrm{PCR}} \mathrm{eVO}_{2 \mathrm{MÁX}}$ comparado aos grupos GCON e GM. O pulso de oxigênio (PULSO de $\mathrm{O}_{2}$ ) que expressa o volume de oxigênio bombeado a cada contração cardíaca, também foi superior nos corredores. Por outro lado, a FC $C_{R E P}$ foi menor no GC, o que sugere um balanço autonômico cardíaco mais aprimorado desses atletas ${ }^{27,28}$. O GC e GM também apresentaram $F C_{P C R}$ e $F C_{P I C O}$ menores que o GCON. A FC Vozmáx foi menor apenas no GC comparado ao GCON.

Os parâmetros ventilatórios durante o TCPE podem ser observados na tabela 3. A VE $E_{L A V}, V E_{P C R}$ e VE $E_{M A ́ x}$ foram maiores no GC quando comparado ao GCON. O GM também apresentou VE $E_{\text {MÁx }}$ maior que o GCON. Os parâmetros de $\mathrm{VCO}_{2}$ foram menores no GCON quando comparado ao GC e GM, com exceção ao parâmetro $\mathrm{VCO}_{2 \mathrm{PCR}}$, que foi menor apenas

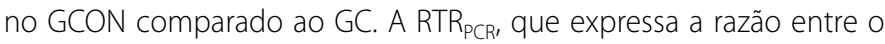
$\mathrm{VCO}_{2} \mathrm{eVO}_{2}$, foi menor para o grupo GM em relação aos demais grupos.

$O$ incremento de carga no decorrer do TCPE e as respectivas velocidades atingidas nos momentos referentes ao LAV, PCR e a velocidade final do teste foi superior no GC comparado aos outros grupos (tabela 4).

A tabela 5 mostra os parâmetros cardíacos, metabólicos e de trabaIho durante a fase de TM. Os corredores apresentaram maior aumento da carga de trabalho e menor alteração do pulso de oxigênio comparado ao GCON e GM. Interessante observar que o $\mathrm{VO}_{2}$ durante a TM não difere entre os grupos.

As figuras 1 e 2 caracterizam o percentual do tempo nos momentos referentes ao LAV (limiar anaeróbio ventilatório), PCR (ponto de compensação respiratória) e MÁX e o coeficiente angular gerado a partir da relação $\mathrm{VO}_{2}$ Vs intensidade ( $E_{\text {INCLNA }}$ ) durante a progressão da intensidade do TCPE, respectivamente. O GC (grupo de corredores de endurance) apresenta um menor $\mathrm{EC}_{\text {INCINA }}$ nos instantes finais do teste confrontados com os demais grupos.

Tabela 1. Características antropométricas e etárias dos grupos.

\begin{tabular}{c|c|c|c}
\hline & GCON $\mathbf{( n = 3 8 )}$ & GM (n =23) & GC $(\mathbf{n}=\mathbf{3 0})$ \\
\hline Idade $(\mathrm{anos})$ & $33 \pm 6(32)$ & $32 \pm 7(30)$ & $38 \pm 8(38)^{*}+$ \\
\hline Estatura $(\mathrm{cm})$ & $176,5 \pm 6,0(176,0)$ & $176,2 \pm 8,7(176,0)$ & $173,3 \pm 6,8(172,0)$ \\
\hline Peso $(\mathrm{Kg})$ & $76,3 \pm 12,5(2,10)$ & $88,3 \pm 14,3(87,4)^{\#^{*}}$ & $68,7 \pm 9,0(71,5)$ \\
\hline IMC $\left(\mathrm{kg} / \mathrm{m}^{2}\right)$ & $23,5 \pm 3,4(23,8)$ & $28,3 \pm 3,6(27,8)^{\#^{*}}$ & $22,7 \pm 2,2(22,3)$ \\
\hline Endomorfia & $5,8 \pm 2,4(5,4)$ & $5,0 \pm 1,6(4,5)$ & $4,1 \pm 1,7(3,7)^{\dagger}$ \\
\hline Mesomorfia & $4,1 \pm 1,2(4,2)$ & $6,7 \pm 1,3(4,1)^{\#^{*}}$ & $4,4 \pm 1,0(4,3)$ \\
\hline Ectomorfia & $2,5 \pm 1,5(2,0)$ & $1,6 \pm 1,2(1,1) \#^{*}$ & $2,6 \pm 1,0(2,8)$ \\
\hline BDC(cm) & $32,4 \pm 3,0(31,9)$ & $41,9 \pm 2,8(42,0) \#^{*}$ & $31,1 \pm 2,3(31,5)$ \\
\hline DCT $(\mathrm{mm})$ & $9,3 \pm 3,6(9,0)$ & $6,2 \pm 2,1(5,9) \#$ & $6,1 \pm 2,2(5,5) \dagger$ \\
\hline
\end{tabular}

valores expressos em média $\pm \mathrm{DP}$ (mediana); *P $<0,05$ vs $\mathrm{GCE} ; \mathrm{P}<0,05$ vs GCON; $\# \mathrm{P}<0,05$ vs GCON; BDC (braço direito contraído); DCT (dobra cutânea tricipital); GCON (grupo controle); GM (grupo musculação); GC (grupo corredores de endurance). 
Tabela 2. Parâmetros cardiorrespiratórios entre os grupos durante o TCPE.

\begin{tabular}{|c|c|c|c|}
\hline & GCON $(n=38)$ & $\mathrm{GM}(n=23)$ & $\mathrm{GC}(n=30)$ \\
\hline $\mathrm{VO}_{2 \perp \mathrm{AV}}\left(\mathrm{ml} / \mathrm{kg} / \mathrm{min}^{1}\right)$ & $24 \pm 6(22)$ & $26 \pm 6(25)$ & $36 \pm 8(35)^{*} \dagger$ \\
\hline $\mathrm{VO}_{2 \mathrm{PCR}}\left(\mathrm{ml} / \mathrm{kg} / \mathrm{min}^{1}\right)$ & $35 \pm 5(35)$ & $35 \pm 6(33)$ & $46 \pm 8(44)^{*} \dagger$ \\
\hline $\mathrm{VO}_{2 M A X} \cdot(\mathrm{ml} / \mathrm{kg} / \mathrm{min})$ & $40 \pm 6(39)$ & $40 \pm 7(40)$ & $51 \pm 8(50)^{*} \dagger$ \\
\hline $\begin{array}{c}\text { Pulso de } \mathrm{O}_{2 L A V} \\
\text { (ml/kg/min } 1 . \mathrm{bpm})\end{array}$ & $0,172 \pm 0,032(0,162)$ & $0,188 \pm 0,032(0,182)$ & $0,321 \pm 0,056(0,321) t^{*}$ \\
\hline $\begin{array}{c}\text { Pulso de } \mathrm{O}_{2 \mathrm{PCR}} \\
\left(\mathrm{ml} / \mathrm{kg} / \mathrm{min}^{1} \mathrm{bpm}\right)\end{array}$ & $0,199 \pm 0,033(0,196)$ & $0,217 \pm 0,039(0,210)$ & $0,273 \pm 0,067(0,274)^{*} \dagger$ \\
\hline $\begin{array}{c}\text { Pulso de } \mathrm{O}_{2 \mathrm{MAx}} \\
\text { (ml/kg/min'.topm) }\end{array}$ & $0,214 \pm 0,041(0,209)$ & $0,224 \pm 0,040(0,215)$ & $0,286 \pm 0,047(0,287) \dagger^{*}$ \\
\hline$F C_{\text {REP }}(\mathrm{bpm})$ & $60 \pm 8(61)$ & $58 \pm 7(57)$ & $52 \pm 6(53) t^{*}$ \\
\hline $\mathrm{FC}_{\mathrm{AVV}}(\mathrm{bpm})$ & $142 \pm 20(141)$ & $140 \pm 20(142)$ & $140 \pm 15(140)$ \\
\hline $\mathrm{FC}_{P C R}(\mathrm{bpm})$ & $174 \pm 14(177)$ & $163 \pm 18(168) \#$ & $165 \pm 14(166) \dagger$ \\
\hline $\mathrm{FC}_{\text {vo2máx. }}(\mathrm{bpm})$ & $185 \pm 15(189)$ & $179 \pm 11(180)$ & $176 \pm 13(177) \dagger$ \\
\hline $\mathrm{FC}_{\mathrm{pICO}}(\mathrm{bpm})$ & $190 \pm 10(189)$ & $181 \pm 8(180) \#$ & $179 \pm 11(178) \dagger$ \\
\hline
\end{tabular}

Valores expressos em média $\pm \mathrm{DP}$ (mediana); ${ }^{*} \mathrm{P}<0,05$ vs $\mathrm{GM} ;+\mathrm{P}<0,05$ vs $\mathrm{GCON}$; \#P $<0,05$ vs $\mathrm{GCON}$ (diferença significativa entre os grupos). ANOVA oneway. LAV (limiar anaeróbio ventilatório); PCR (ponto de compensação respiratória); REP (repouso); FC (frequência cardíaca); GCON (grupo controle); GM (grupo musculação); GC (grupo corredores de endurance).

Tabela 3. Parâmetros ventilatórios durante o TCPE.

\begin{tabular}{|c|c|c|c|}
\hline & GCON $(n=38)$ & GM $(n=23)$ & GC $(n=30)$ \\
\hline$V E_{\mid A V}$ & $45 \pm 14(44)$ & $54 \pm 12(54)$ & $62 \pm 14(59) \dagger$ \\
\hline$V E_{P C R}$ & $74 \pm 18(70)$ & $82 \pm 15(80)$ & $93 \pm 17(96) \dagger$ \\
\hline$V E_{\text {MÁX }}$ & $91 \pm 16(92)$ & $105 \pm 16(101) \#$ & $108 \pm 16(112) \dagger$ \\
\hline $\mathrm{VCO}_{2 \perp \mathrm{AV}}$ & $1,64 \pm 0,51(1,54)$ & $2,09 \pm 0,49(2,11) \#$ & $2,39 \pm 0,56(2,26) \dagger$ \\
\hline $\mathrm{VCO}_{2 \mathrm{PCR}}$ & $2,82 \pm 0,64(2,74)$ & $3,11 \pm 0,52(3,06)$ & $3,45 \pm 0,54(3,41) \dagger$ \\
\hline $\mathrm{VCO}_{2 \mathrm{MÁx}}$ & $3,33 \pm 0,67(3,74)$ & $3,91 \pm 0,66(3,27) \#$ & $4,04 \pm 0,54(4,00) \dagger$ \\
\hline $\mathrm{RTR}_{\mathrm{IAV}}$ & $0,92 \pm 0,10(0,92)$ & $0,92 \pm 0,07(0,90)$ & $0,98 \pm 0,19(0,95)$ \\
\hline $\mathrm{RTR}_{\mathrm{PCB}}$ & $1,09 \pm 0,08(1,08)^{*}$ & $1,03 \pm 0,05(1,02)$ & $1,12 \pm 0,20(1,08)^{*}$ \\
\hline $\mathrm{RTR}_{\text {MÁX }}$ & $1,16 \pm 0,07(1,15)$ & $1,12 \pm 0,07(1,12)$ & $1,17 \pm 0,12(1,16)$ \\
\hline $\mathrm{VE} / \mathrm{NO}_{2 \mid \mathrm{AV}}$ & $24 \pm 12(22)$ & $23 \pm 3(22)$ & $24 \pm 3(24)$ \\
\hline $\mathrm{VE} / \mathrm{NO}_{2 \mathrm{PCR}}$ & $27 \pm 4(27)$ & $26 \pm 3(26)$ & $28 \pm 4(28)$ \\
\hline $\mathrm{VE} / \mathrm{NO}_{2 \mathrm{MAX}}$ & $31 \pm 4(30)$ & $29 \pm 3(28)$ & $30 \pm 4(30)$ \\
\hline $\mathrm{VE} / \mathrm{NCO}_{2 \perp \mathrm{AV}}$ & $25 \pm 2(25)$ & $24 \pm 2(24)$ & $25 \pm 2(25)$ \\
\hline $\mathrm{VE} / \mathrm{NCO}_{2 \mathrm{PCR}}$ & $25 \pm 3(26)$ & $25 \pm 2(25)$ & $26 \pm 2(25)$ \\
\hline VENCOO 2 MÁX & $27 \pm 3(26)$ & $26 \pm 2(26)$ & $26 \pm 2(25)$ \\
\hline $\mathrm{PetO}_{2 \perp \mathrm{AV}}$ & $99 \pm 6(101)$ & $100 \pm 6(99)$ & $102 \pm 5(102)$ \\
\hline $\mathrm{PetO}_{2 \mathrm{PCR}}$ & $107 \pm 5(107)$ & $105 \pm 5(104)$ & $107 \pm 5(106)$ \\
\hline $\mathrm{PetO}_{2 \text { MÁx }}$ & $110 \pm 5(110)$ & $108 \pm 4(107)$ & $108 \pm 4(109)$ \\
\hline $\mathrm{PetCO}_{2 \perp \mathrm{AV}}$ & $42 \pm 3(43)$ & $43 \pm 4(42,2)$ & $42 \pm 3(41,3)$ \\
\hline $\mathrm{PetCO}_{2 \mathrm{PCR}}$ & $42 \pm 4(41)$ & $42 \pm 4(42)$ & $41 \pm 4(40)$ \\
\hline $\mathrm{PetCO}_{2 \mathrm{MÁx}}$ & $40 \pm 4(40)$ & $40 \pm 4(40)$ & $40 \pm 4(40)$ \\
\hline
\end{tabular}

Valores expressos em média $\pm \mathrm{DP}$ (mediana); ${ }^{\mathrm{P}}<0,05$ vs $\mathrm{GM} ; \mathrm{TP}<0,05$ vs $\mathrm{GCON}$; $\# \mathrm{P}<0,05$ vs $\mathrm{CON}$; VE (ventilação minuto); $\mathrm{VCO}_{2}$ (produção de dióxido de carbono); RTR (razão de troca respiratória); VE/NCO2 (equivalente ventilatório de dióxido de carbono); $\mathrm{PetO}_{2}$ (pressão expirada de oxigênio); $\mathrm{PetCO}_{2}$ (pressão expirada de dióxido de carbono); LAV (limiar anaeróbio ventilatório); PCR (ponto de compensação respiratória); GCON (grupo controle); GM (grupo musculação); GC (grupo corredores de endurance).

Tabela 4. Características de Incremento no TCPE.

\begin{tabular}{|c|c|c|c|}
\hline & GCON $(n=38)$ & GM $(n=23)$ & $\mathrm{GC}(n=30)$ \\
\hline $\begin{array}{c}\text { Incremento de carga } \\
(\mathrm{km} / \mathrm{min})\end{array}$ & $0,69 \pm 0,10(0,69)$ & $0,78 \pm 0,11(0,79)$ & $1,10 \pm 0,27(1,06)^{*} \dagger$ \\
\hline Velocidade LAV (km/h) & $7,7 \pm 1,2(7,4)$ & $8,1 \pm 1,3(7,8)$ & $11,1 \pm 2,3(10,9)^{*} \dagger$ \\
\hline Velocidade PCR (km/h) & $10,6 \pm 1,8(10,3)$ & $10,8 \pm 1,6(11,0)$ & $15,2 \pm 2,4(15,3)^{*} \dagger$ \\
\hline Velocidade final (km/h) & $12,8 \pm 2,0(12,9)$ & $12,8 \pm 1,7(12,6)$ & $17,5 \pm 2,9(16,8)^{*} \dagger$ \\
\hline
\end{tabular}

Tabela 5. Parâmetros cardíacos, metabólicos e de trabalho na fase de transição metabólica.

\begin{tabular}{|c|c|c|c|}
\hline & GCON $(n=38)$ & GM $(n=23)$ & $G C(n=30)$ \\
\hline CARGA (km/h) & $2,7 \pm 1,6(2,2)$ & $2,8 \pm 1,0(2,7)$ & $4,2 \pm 1,6(4,1)^{*}+$ \\
\hline $\mathrm{VO}_{2}\left(\mathrm{ml} / \mathrm{kg} / \mathrm{min}^{-1}\right)$ & $10 \pm 5(10)$ & $9 \pm 4(8)$ & $10 \pm 5(10)$ \\
\hline PULSO de $\mathrm{O}_{2}$ & $0,025 \pm 0,022(0,022)$ & $0,029 \pm 0,024(0,027)$ & $-0,036 \pm 0,067(-0,047)^{*} \dagger$ \\
\hline $\mathrm{FC}(\mathrm{bpm})$ & $33 \pm 16(28)$ & $24 \pm 15(22)$ & $25 \pm 17(28)$ \\
\hline $\operatorname{VE}(1 / \mathrm{min})$ & $28 \pm 16(25)$ & $29 \pm 13(26)$ & $30 \pm 16(27)$ \\
\hline $\mathrm{VCO}_{2}$ & $1,17 \pm 0,62(0,96)$ & $1,05 \pm 0,45(0,98)$ & $1,05 \pm 0,61(1,15)$ \\
\hline RTR & $0,17 \pm 0,11(0,17)$ & $0,12 \pm 0,06(0,11)$ & $0,15 \pm 0,10(0,14)$ \\
\hline $\mathrm{VE} / \mathrm{NCO}_{2}$ & $0,35 \pm 1,60(0,10)$ & $0,69 \pm 1,14(0,50)$ & $0,49 \pm 1,46(0,10)$ \\
\hline $\mathrm{PETO}_{2}$ & $5,5 \pm 4,6(5,1)$ & $4,4 \pm 3,3(5,0)$ & $4,7 \pm 3,7(4,8)$ \\
\hline $\mathrm{PETCO}_{2}$ & $-0,6 \pm 2,7(-0,40)$ & $-0,8 \pm 1,8(-0,8)$ & $-1,0 \pm 1,9(-0,7)$ \\
\hline
\end{tabular}

Valores expressos em média $\pm D P$ (mediana) : ${ }^{*} \mathrm{P}<0,05$ vs $\mathrm{GM} ;{ }^{+} \mathrm{P}<0,05$ vs GCON (diferença significativa entre os

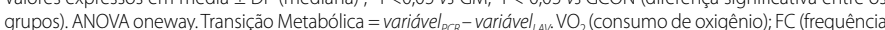

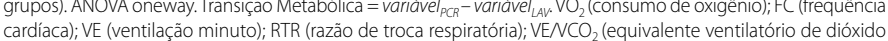
de carbono); $\mathrm{PetO}_{2}$ (pressão expirada de oxigênio); $\mathrm{PetCO}_{2}$ (pressão expirada de dióxido de carbono); GCON (grupo controle); GM (grupo musculação); GC (grupo corredores de endurance).

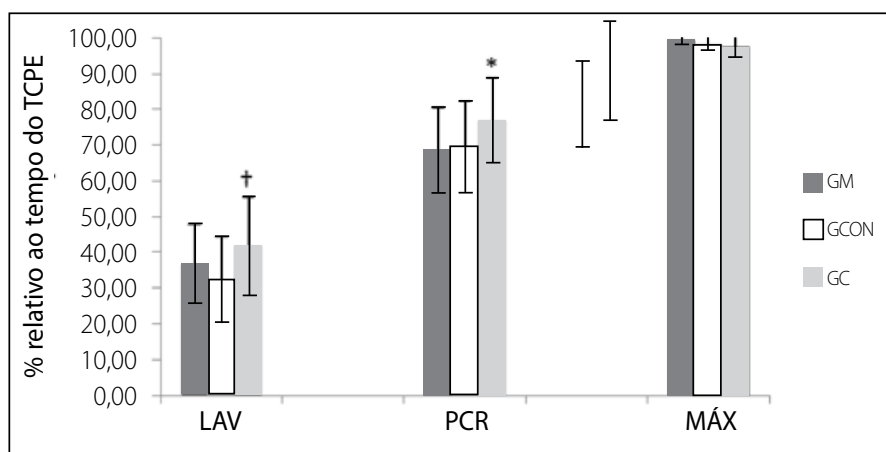

LAV (limiar anaeróbio ventilatório), PCR (ponto de compensação respiratória) e VO ${ }_{2 \text { máx }}$ (consumo máximo de oxigênio). GM (grupo musculação). GCON (grupo controle). GC (grupo de corredores de endurance). ${ }^{*} \mathrm{P}<0,05 \mathrm{vs}$ ERI; ${ }^{+} \mathrm{P}<0,05$ vsCON. ANOVA oneway. Valores em média $\pm \mathrm{DP}$.

Figura 1. Percentual relativo ao tempo total do teste cardiopulmonar de exercício nos momentos referentes ao LAV, PCR, VO ${ }_{2 \text { máx }}$.

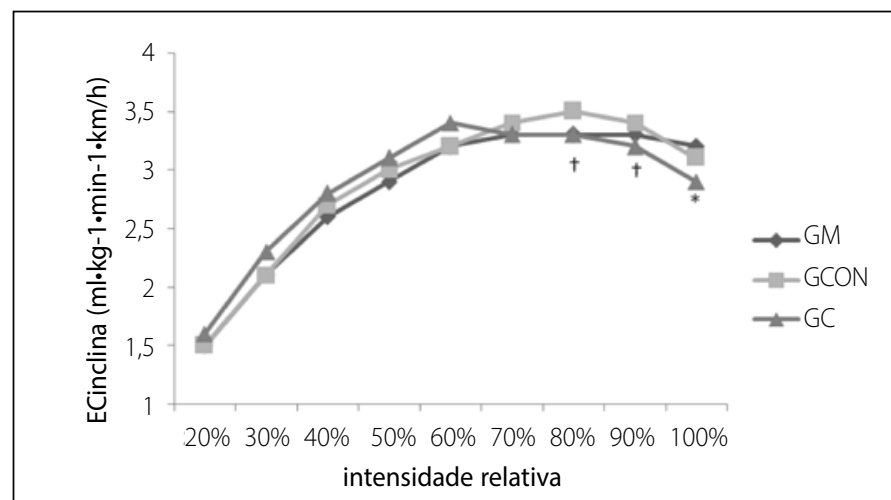

GM (grupo musculação). GCON (grupo controle). GC (grupo de corredores de endurance). ${ }^{\dagger} \mathrm{P}<0,05$ diferença entre CE vs CON. *P<0,05 diferença entre CE vs ERI. Anova one way. Valores em média.

Figura 2. $E C_{\text {INCLINA }}$ (coeficiente angular gerado pela relação entre $\mathrm{VO}_{2} \mathrm{Vs}$ intensidade) durante o TCPE (teste cardiopulmonar de exercício).

\section{DISCUSSÃO}

O principal resultado do presente estudo é que não há diferenças entre praticantes de musculação e não praticantes de exercício para as variáveis cardiorrespiratórias investigadas por meio do teste cardiopulmonar de exercício, confirmando parcialmente nossa hipótese, já que apenas o GC apresentou diferenças em relação aos outros dois grupos.

Os parâmetros antropométricos e os valores de $\mathrm{VO}_{2 \mathrm{MAX}}$ confirmam que a estratificação dos grupos foi adequada. Indivíduos submetidos por longo prazo ao treinamento físico apresentam adaptações morfológicas que diferem dos indivíduos fisicamente não ativos ${ }^{28}$. De fato, 0 peso corporal e o índice de massa corpórea (IMC) são bem maiores em praticantes de exercícios resistidos intensos. A análise do somatotipo auxilia na interpretação de que o maior peso e IMC não podem ser atribuídos a maior massa de gordura, uma vez que a mesomorfia, que indica o grau de proeminência muscular é superior nestes sujeitos quando comparados ao grupo GC e grupo GCON. Também já era esperado que o GC apresentasse maior média para $\mathrm{VO}_{2 \mathrm{MÁ} x}$, uma vez que a máxima capacidade do organismo de absorver, transportar e consumir $\mathrm{O}_{2}$ aumentam com o treinamento de corrida de longa distância ${ }^{26}$.

No presente estudo, o momento de acontecimento do LAV foi mais tardio no GC, quando relativizado ao tempo total do TCPE, comparado ao GCON e GM (figura 2). Na literatura encontramos que as adaptações periféricas associadas ao aumento da capacidade oxidativa muscular são responsáveis pelo aumento do LAV e que esta elevação está relacionada a um condicionamento aeróbio superior' ${ }^{1}$ No PCR, a diferença existente ocorre entre o GC e GM, o que parece indicar que os corredores permaneceram maior tempo na TM sugerindo que, em relação ao GCON e ao GM, tais atletas suportam maior acúmulo de lactato sanguíneo ou apresentam um mecanismo de tamponar mais acurado ${ }^{16-18}$. 
$\mathrm{OVO}_{2 \mathrm{MAx}}$ tem sido reportado na literatura como índice que expressa a capacidade aeróbia25,27,29. Embora os exercícios de média e longa duração sejam altamente dependentes da energia produzida pelo metabolismo aeróbio, o VO $\mathrm{V}_{2 \mathrm{MAx}}$ pode não ser um bom preditor da performance da atividade de endurance, uma vez que atletas com mesmo $\mathrm{VO}_{2}$ podem apresentar variações na performance por influência de diferentes fatores.

Entre esses fatores, está a economia de corrida (EC) que pode ser definida como o estado estável do $\mathrm{VO}_{2}$ para uma dada velocidade submáxima ou distância ${ }^{12-15}$, e na habilidade do sistema neuromuscular em produzir potência durante o exercício ${ }^{23}$. Contudo, a mensuração da EC envolve a aplicação de 2-3 testes o que poderia desencorajar a mensuração desta variável. Nesse sentido, trabalhos prévios ${ }^{20,21}$, deter-

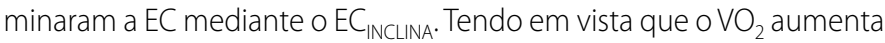
continuamente durante o TCPE até o valor máximo ser atingido ${ }^{25}$, é de se esperar que atletas mais econômicos apresentem um menor

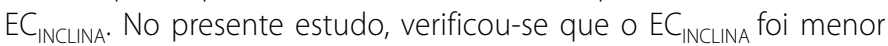
entre o GC e GCON nas intensidades de $80 \%$ e $90 \%$ do tempo total do TCPE e a 100\% houve diferença entre o GM e GC (figura 2), o que seria indicativo de uma melhor eficiência de corrida para o GC em relação a praticantes de musculação e não praticantes de exercícios. Apesar da utilização do treinamento de força para ganho de potência por atletas que praticam a corrida ${ }^{22-24}$, o treinamento de força isolado parece não promover alterações nesta variável quando comparado ao grupo GCON. Além disso, o treinamento de força com altas cargas não é considerado ter impacto sobre o $\mathrm{VO}_{2 \mathrm{MAX}}{ }^{30}$. De fato, no presente estudo não houve diferenças no $\mathrm{VO}_{2}$ nos momentos referentes ao LAV, PCR e MÁX entre o GM e GCON.

No presente estudo a limitação foi que o lactato e bicarbonato sanguíneos não foram dosados. No entanto, encontramos na literatura estudos ${ }^{9,12}$ que reportam similaridade entre os pontos identificados invasivamente e o LAV e PCR identificados por parâmetros ventilatórios. De fato, o uso de diferentes terminologias para determinação dos limiares pode estar atrelado aos critérios adotados, às características dos sujeitos estudados, ou ainda à utilização de diferentes tipos de exercício e/ou protocolos com variações nas intensidades de incremento da carga e duração dos estágios. Alguns autores, por exemplo, analisaram

\section{REFERÊNCIAS}

1. Garber CE, Blissmer B, Deschenes MR, Franklin BA, Lamonte MJ, Lee IM, et al. American College of Sports Medicine position stand. Quantity and quality of exercise for developing and maintaining cardiorespiratory, musculoskeletal, and neuromotor fitness in apparently healthy adults: guidance for prescribing exercise. Med Sci Sports Exerc. 2011:43(7):1334-59.

2. Green H, Goreham C, Ouyang J, Ball-Burnett M, Ranney D. Regulation of fiber size, oxidative potential, and capillarization in human muscle by resistance exercise. Am J Physiol. 1999;276(2 Pt 2):R591-6.

3. Wasserman K, Hansen JF, Sue UY, Casaburi R, Whipp BJ. Prova de esforço: princípios e interpretação.3a ed. Rio de Janeiro: Revinter; 2005.

4. Tanaka $\mathrm{H}$, Swensen $\mathrm{T}$. Impact of resistance training on endurance performance. A new form of cross-training? Sports Med. 1998;25(3):191-200.

5. Ghosh AK. Anaerobic threshold: its concept and role in endurance sport. Malays J Med Sci. 2004;11(1):24-36

6. Beaver WL, Wasserman K, Whipp BJ. A new method for detecting anaerobic threshold by gas exchange. J Appl Physiol (1985). 1986;60(6):2020-7.

7. Leal Junior ECP, Souza FB, Magini M, Martins RAB. Estudo comparativo do consumo de oxigênio e limiar anaeróbio em um teste de esforço progressivo entre atletas profissionais de futebol e futsal. Rev Bras Med Esporte. 2006;12(6):323-26

8. LourençoT, Tessuti LS, Martins LEB, Brenzikofer R, Macedo DV. Interpretação metabólica dos parâmetros ventilatórios obtidos durante um teste de esforço máximo e sua aplicabilidade no esporte. Rev Bras Cineantropom Desempenho Hum. 2007;9(3): 303-10.

9. Pithon KR, Martins LEB, Gallo JRL, Catai AM, Silva E. Comparação das Respostas Cardiorrespiratórias entre Exercício de Carga constante e incremental abaixo, acima e no limiar de anaerobiose ventilatório. Rev Bras Fisioter. 2006;10(2):163-9.

10. Beaver WL, Wasserman K, Whipp BJ. Bicarbonate buffering of lactic acid generated during exercise. J Appl Physiol (1985). 1986;60(2):472-8.

11. Chicharro JL, Hoyos J, Lucía A. Effects of endurance training on the isocapnic buffering and hypocapnic hyperventilation phases in professional cyclists. Br J Sports Med. 2000;34(6):450-5.

12. Dickhuth HH, Yin L, Niess A, Röcker K, Mayer F, Heitkamp HC, et al. Ventilatory, lactate-derived and catecholamine thresholds during incremental treadmill running: relationship and reproducibility. Int J Sports Med. 1999;20(2):122-7.

13. Pupo J, Souza KM, Arins FB, Guglielmo GA, Santos SG. Características Fisiológicas de Corredores MeioFundistas de diferentes níveis Competitivos. Rev Educ Fís. 2011;22(1):119-27.

14. Denadai BS, Ortiz M, Mello M. Índices fisiológicos associados com a "performance" aeróbia em corredores de "endurance": efeitos da duração da prova. Rev Bras Med Esporte. 2004;10(5):401-4.

15. Caputo F, Oliveira MF, Greco CC, Denadai BS. Exercício aeróbio: aspectos bioenergéticos, ajustes fisioló- a relação entre a reprodutibilidade das intensidades do limiar anaeróbio individual e limiar ventilatório determinado pelo método v-slope. Os autores encontraram alta reprodutibilidade da velocidade de corrida no limiar de lactato $(r=0,90)$, no limiar anaeróbio individual $(r=0,97)$, no limiar ventilatório $(r=0,88)$ e no ponto de compensação respiratória ( $r=0.95)$. Em ambos os testes foi encontrada uma forte correlação $(r=0,97 ; p<0,01)$ entre o limiar anaeróbio individual e o ponto de compensação respiratória9,12. Diante disso, embora fosse importante mensurar a concentração sanguínea de lactato e bicarbonato durante as fases de transição no TCPE, os estudos citados permitem assumir que a interpretação dos limiares por parâmetros ventilatórios apresenta similitude com os limiares detectados invasivamente.

Finalmente, é importante assumir que, o fato dos corredores apresentarem idade superior aos demais poderia colocá-los em condições mais desfavoráveis. Contudo, isso não é observado nos resultados desse estudo, e por isso nos parece desnecessário a correção dos resultados pela idade.

\section{CONCLUSÃO}

Há evidência de uma maior eficiência metabólica entre os corredores, para transições progressivas de intensidade de esforço em relação aos demais grupos. Além disso, pode-se concluir que os praticantes de exercícios resistidos intensos não exibem uma capacidade de transição aprimorada nas progressões do exercício, até mesmo quando comparados a indivíduos sedentários. Esses achados sugerem que a especificidade do treino é um importante princípio a se considerar, também para a fase da transição metabólica, reforçando a necessidade de se incluir atividades aeróbicas para se obter efeitos sobre a fase da TM.

\section{AGRADECIMENTOS}

Os autores agradecem a Fundação de Amparo à Pesquisa do Espírito Santo (FAPES) pelo apoio dado a este trabalho e aos atletas que gentilmente colaboraram com esse estudo.

Todos os autores declararam não haver qualquer potencial conflito de interesses referente a este artigo. gicos, fadiga e índices de desempenho. Rev Bras Cineantropom Desempenho Hum. 2009;1 1(1):94-102. 16. Souza KM, Viera G, Baldi MF, Guglielmo LGA, Lucas RD, Denadai BS. Variáveis fisiológicas e neuromusculares associadas com a performance aeróbia em corredores de endurance: efeitos da distância da prova. Rev Bras Med Esporte. 2011;17(1):40-4.

17. Juel C. Muscle pH regulation: role of training. Acta Physiol Scand. 1998;162(3):359-66.

18. Chicharro JL, Carvajal A, Pardo J, Pérez M, Lucía A. Physiological parameters determined at OBLA vs. a fixed heart rate of 175 beats $\times$ min- 1 in an incremental test performed by amateur and professional cyclists. Jpn J Physiol. 1999;49(1):63-9.

19. Röcker K, Striegel H, Freund T, Dickhuth HH. Relative functional buffering capacity in 400-meter runners, long-distance runners and untrained individuals. Eur J Appl Physiol Occup Physiol. 1994;68(5):430-4.

20. Carmo E, Barreti DLM, Ugrinowitsch C, Tricoli V. Estratégia de corrida em média e longa distância: como ocorrem os ajustes ao longo da prova? Rev Bras Educ Fís Esporte. 2012;26(2):351-63.

21. Bertuzzi RCM, Bueno S, Pasqua LA, Batista MB, Roschel H, Acquesta FM, et al. É possível determinar a economia de corrida através do teste progressivo até a exaustão? Rev Bras Educ Fís Esporte. 2010;24:373-8

22. Fernandes RJ, Billat VL, Cruz AC, Colaço PJ, Cardoso CS, Vilas-Boas JP. Does net energy cost of swimming affect time to exhaustion at the individual's maximal oxygen consumption velocity? J Sports Med Phys Fitness. 2006;46(3):373-80.

23. Scott CB. Quantifying the immediate recovery energy expenditure of resistance training. J Strength Cond Res. 2011:25(4):1159-63.

24. Silva P, Trindade R, Rose E. Composição corporal, somatotipo e proporcionalidade de culturistas de elite do Brasil. Rev Bras Med Esporte. 2003;9(6): 403-07.

25. Howley ET, Bassett DR Jr, Welch HG. Criteria for maximal oxygen uptake: review and commentary. Med Sci Sports Exerc. 1995;27(9):1292-301.

26. Sloan RP, Shapiro PA, DeMeersman RE, Bagiella E, Brondolo EN, McKinley PS, et al. The effect of aerobic training and cardiac autonomic regulation in young adults. Am J Public Health. 2009;99(5):921-8.

27. Smith DA, O'Donnell TV. The time course during 36 weeks' endurance training of changes in Vo 2 max. and anaerobic threshold as determined with a new computerized method. Clin Sci (Lond). 1984:67(2):229-36.

28. Lunz W, Miranda RN, Dantas EM, Morra EAS, Carletti L, Perez AJ, et al. Comparação da resposta autonômica cardiovascular de praticantes de musculação, corredores de longa distância e não praticantes de exercício. Rev Bras Educ Fís Esporte. 2013;27(4): 531-41.

29. Denadai BS, Figueira TR, Favaro OR, Gonçalves M. Effect of the aerobic capacity on the validity of the anaerobic threshold for determination of the maximal lactate steady state in cycling. Braz J Med Biol Res. 2004;37(10):1551-6.

30. Bishop D, Jenkins DG, Mackinnon LT, McEniery M, Carey MF. The effects of strength training on endurance performance and muscle characteristics. Med Sci Sports Exerc. 1999;31(6):886-91. 